\title{
Digitization and Developing Digital Library and Information Support in Bangladesh: Professional Challenges
}

\begin{abstract}
Md. Saiful Alam ${ }^{1}$
Abstract

The digital revolution throughout the world has brought about new challenges as well as new opportunities for the information professionals. The information professionals of the developing countries are grappling with problems like weak infrastructure, lack of skilled manpower, financial stringency etc. in implementing information and communication technologies in the libraries and also in the digitization of information resources. This paper explores the problems and potential of ICT and digitization in context of the library and information sector of Bangladesh. An elaborate analysis of various challenges for establishing digital information systems and services in the backdrop of the socio-economic realities of Bangladesh has been presented in the paper, along with indications as to how these challenges could be overcome. The paper ends with the conviction that, if these challenges could be dealt with successfully, the Vision 2021 stated by the Government could be realized in time.
\end{abstract}

Keyword: Digitization, Information support, Bangladesh.

With the development and expansion of the Internet in the 1990s, archives, libraries and museums started to make digital copies of their documents and objects in order to use modern Information Communications Technologies (ICT) to make their information and knowledge easily accessible irrespective of institutional, socio-political and geographical boundaries. With the increased availability of economical digital storage media, high speed scanners and high-bandwidth networks, digital libraries have received a boost in the last few years. The dream of digitizing the vast knowledge of mankind, and making it available online has now become a realizable goal even for the information professionals of Bangladesh. According to the available literature, the computerization process of libraries in Bangladesh was started in the early 1990s and up to this time around 50-60\% urban based libraries and information centers have started using computer and related technologies in their activities. Except a few, these activities are basically confined in official works in-house database maintenance, and some times in static website maintenance. Less access to computing technologies, low economic condition and poor ICT infrastructure, socio-political instability, lack of efficient manpower etc. are considered as barriers to technology based library systems in the country. This scenario entails that there exist a long gap between the vision 2021 and the reality of 2021

${ }^{1}$ Associate Professor, Department of Information Science and Library Management, University of Dhaka. E-mail: saifulalam.du@gmail.com 


\section{Bangladesh Journal of Library and Information Science}

and the success story of "The Digital Bangladesh" will depend on the development of digital knowledge source and its diffusion. Thus the creation of a digital knowledge base, place it on the common platform of the information-super-highway and ensure the accessibility to the relevant knowledge sources are the real challenges of our information professionals today.

Development of sustainable digital information support is really a challenging job particularly for developing country like Bangladesh. The National Library of New Zealand (NLNZ) has mentioned these challenge indicators in the definition of a digital library- 'the infrastructure, policies and procedures, and organizational, political and economic mechanisms necessary to enable access to and preservation of digital content.' Considering these issues and socio-economic condition of Bangladesh, this paper explores existing policies, current scenario and professional challenges toward digitization and digital information systems development in Bangladesh.

\section{Policy matter National Education Policy 2010 and digital library system}

The library has been considered as the mirror of civilization in the National Education Policy 2010. There are some important policy directions in the education policy. The objectives and strategy of library programs in the education system have been expressed in the chapter 20. The broader strategic objective of library program will be "to enrich the library collection with adequate books and journals at all levels and bring libraries under digital systems gradually." However, different aspects of policy directions relating to library and digital librarianship are accumulated in Table 1.

Table 1: Policy direction relating to digitization and ICT based library systems in the National Education Policy 2010

\begin{tabular}{|l|l|}
\hline \multicolumn{1}{|c|}{ Chapter } & \multicolumn{1}{c|}{ Strategy } \\
\hline 20. Library & $\begin{array}{l}\text { 2. Public libraries will be set up at every Upazila Headquarters which } \\
\text { will be responsible for supplying books to primary/secondary schools. } \\
\text { 7. Well-Stocked libraries will be established in every college and } \\
\text { universities. Electronic copies of research journals will be collected. } \\
\text { Libraries will be connected with the help of networks so that any student } \\
\text { can enjoy the facilities from any library. Gradually, digital version of } \\
\text { books and journals will be brought out. }\end{array}$ \\
\hline $\begin{array}{l}\text { 26. Curriculum, } \\
\text { syllabus and } \\
\text { textbooks }\end{array}$ & $\begin{array}{l}\text { 8. Considering the importance of National Library and National } \\
\text { Archives, their organizational structure will be rearranged and will be } \\
\text { brought under the digital system. There will be a research and training } \\
\text { section and this section will be provided with ICT facilities. }\end{array}$ \\
\hline $\begin{array}{l}\text { 11. Science } \\
\text { education }\end{array}$ & $\begin{array}{l}\text { 10. Steps will be taken so that students can easily receive text and reference } \\
\text { books. For this purpose, library development and the use of IT in libraries will } \\
\text { be ensured. } \\
\text { 12. Research journals will be published to widely disseminate the } \\
\text { outcomes of research among all. At the same time, necessary steps will } \\
\text { also be taken to make research journals from around the world available } \\
\text { to local researchers. All libraries of the country will be connected } \\
\text { through information technology and networks. }\end{array}$ \\
\hline
\end{tabular}




\section{Bangladesh Journal of Library and Information Science}

The National Education Policy 2010 has given due emphasis on the establishment of libraries and information center up to the upazilla level, simultaneous collection development as well as modernization with ICT based activities. It urges to establishment of digital system for the national and archives as well as digital repository with books and journals and networking and resource sharing among the academic libraries across the country.

\section{National ICT Policy 2008 and digitization}

In October 2002, the Government of the People's Republic of Bangladesh declared the first national policy on ICT known as the 'National ICT Policy 2002' with a vision for "a knowledge-based society' in the country by 2006 as a terminal goal”. In 2008 a committee reviewed the implementation status of the ICT policy 2002 which had 103 policy directives in 16 areas. Among those, 8 were fully or largely accomplished, 61 were partially accomplished and 34 remained unaddressed. The second ICT Policy has been released in 2008 with a central vision "Expand and diversify the use of ICTs to establish a transparent, responsive and accountable government; develop skilled human resources; enhance social equity; ensure cost-effective delivery of citizen-services through public-private partnerships; and support the national goal of becoming a middle-income country within ten years and join the ranks of the developed countries of the world within thirty years" and aims at "Bangladesh is expected to become a 'knowledge society' within one generation” (MoSICT, National ICT Policy -2008, p.3).

The policy document is structured as a hierarchical pyramid having three layers on its vision statements.

The first layer includes 10 broader objectives- (1) Social equity (2) Productivity (3) Integrity (4) Education and research (5) Employment (6) Strengthening exports (7) Healthcare (8) Universal access (9) Environment, climate and disaster management (10) Support to ICTs. The second and third layer includes 56 strategic themes and 306 action items. Unfortunately, library system could not take its position neither in the 10 broader objectives nor in the 56 strategic themes. However, digital library systems and its different aspects of ICT applications in libraries have been reflected in different action items in the strategic themes shown in table 2.

Source: National ICT Policy 2008 (proposed)

* In the long range planning, Central Public Library and divisional branches and all district branches are to be included gradually. There is a special argument for building a National Research and Educational Network. The action plan 152 urges to bring all universities including Open University under a National Research and Education Network (NREN) and in 153 to bring all colleges under National University under this network.

** Upon implementation the government targets to reduce $75 \%$ costs particularly for ICT industry.

*** May create opportunity to enter into e-governance and paperless society. 


\section{Bangladesh Journal of Library and Information Science}

**** Action plan 281, 291-94 will help all students access to knowledge of ICT, get connected to internet at an affordable price and to reduce digital divide between rural and urban. There is scope for taking necessary action steps for digitization, e-books, ejournals production and promotion but unfortunately nothing is found.

Open source software has been encouraged in all educational institutes to enhance learning and knowledge creation in the ICT policy 2008. We are expecting a clear strategic activity relating to knowledge digitization, or institutional repository, knowledge base etc. but unfortunately we found nothing relating to building ICT infrastructure or institutional capacity building for digital knowledge base, digital library systems. We think that the absence of such clause may hinder the digitization and digital library system stated in the education policy.

\section{Current Scenario}

There is no recent institutional statistics supporting neither the actual number of libraries and information centers in Bangladesh nor ICT usage in the existing library systems. According to different personal investigation and survey it has been evident that there exists neither digital library nor any integrated automated library system in the country in true sense of the term (Alam: 2007, p 96). Another fact is that at present around $60 \%$ urban based libraries and information centers have brought computer and other ICT equipment in use. Digitization and automated library systems in Bangladesh are still in the infancy level. In the recent times a very few initiatives have been noticed taken by different institutions as project work. These institutions are BANBEIS, BRAC university library, ICDDR,B publication unit, The National Library of Bangladesh, BIDS library etc. The activities of these projects include the acquisition and subscription of e-books and e-journals, digitization of paper based documents through scanning and Desk Top Publishing (DTP), developing database or online repository for metadata and full-text, providing searching and downloading facilities (online and offline), document and user profiling etc. It is to be mentioned here that some academic and research libraries in Bangladesh having online access to e-journal as member of INASP/PERI consortium. The INASP/PERI - International Network for the Availability of Scientific Publications /Program for Enhancement of Research Information - consortium is an on-line journal network started in 2006 and Bangladesh has been subscribing its services since 2008 .

\section{Challenges}

Establishment of digital preservation system and digital library system is difficult, expensive and long-term process. Particularly in the developing countries, like Bangladesh, the process comes across some serious challenges. The National Digital Library Program at the Library of Congress have identified ten technical challenges that must be met if large and effective digital libraries are to be created during the 21st century (LC: 1999). The technical challenges are grouped under some broad categories: building the resource, interoperability, intellectual 
property, providing effective access, and sustaining the resource. An attempt has been made to look into the applicability and the extent of these professional challenges as well as other challenges toward digital information systems and services considering the socio-economic and other factors of the country.

Challenge One: Adopt improved technology for digitizing analog materials. User groups particularly in higher education and research are increasingly dependent on epublication. in respond to the research need libraries in Bangladesh have to build a comprehensive resource, historical materials now in analog form (e.g., books, journals, laboratory records, sound recordings, manuscripts, photographs) must be converted. Today, the technology for digital conversion is emergent and there are few established standards on which they have to ensure reproduction quality. Unfortunately most of the information professionals are not well verged about the equipment and their applications let alone the standard of digitization. Cost of some essential equipment e.g. high speed scanner, communication switch, storage servers are still beyond the library budget.

Challenge Two: Design search and retrieval tools that compensate for abbreviated or incomplete cataloging or descriptive information.

Providing access to library collections is labor-intensive. In digitization there is a need for more automated support for capturing explicit data structures, generating descriptive elements, re-keying and encoding texts and indexing the full-text. There is an inadequacy of such sort of efficient human resources in the libraries of Bangladesh. As a result, we have to depend on commercial digitization which is not also less expensive.

Challenge Three: Design tools that facilitate the enhancement of cataloging or descriptive information by incorporating the contributions of users.

Can the digital library take advantage of distributed expertise? Among millions of users, there will be those who can enhance the description or cataloging of an item, thus improving the next researcher's chance of finding it. Collaborative tools could allow far-flung professional colleagues. Unfortunately due to centralized in-house function and absence of networking among the libraries such sort of facilities are absent in the library systems in Bangladesh.

\section{Challenge Four: Establish protocols and standards for Interoperability.}

According to ISO Information Technology Vocabulary, Interoperability is the capability to communicate, execute programs, or transfer data among various functional units in a manner that requires the user to have little or no knowledge of the unique characteristics of those units. This indicates if the digitization programs exist on some standard and protocol such as Z39.50, USMARC-3 or Dublin Core Metadata encodes or the approached used by World Wide Web search engines, information can be shared across the heterogeneous network made up of several local area networks. The Library of Congress research team considers it as a challenge and urges to establish the necessary protocol and standard to facilitate the assembly of distributed digital libraries. Though some libraries in Bangladesh have initiated to develop digital collection, they hardly follow any international standard but the set procedure in the software without customization. These discrete procedures may be workable in intranet but loss the opportunity of sharing resources at a large platform at extranet. 


\section{Bangladesh Journal of Library and Information Science}

\section{Challenge Five: Addressing legal issues of intellectual property}

A key element for digital libraries is recognition and protection of legal rights such as copyright, publicity, privacy, matters of obscenity, defamation intellectual property protection as well as less legalistic but serious concerns associated with the ethics of sharing or providing access to digital contents. This is often in conflict with the duties of libraries and archives entrusted with care and management of materials that may be subject to privacy rights or other needs for security. The LC has precisely mentioned about the intellectual property act that

Efforts to formulate digital libraries will be delayed or frustrated in the absence of a common, responsible framework of rights, permissions, and restrictions that acknowledges the mutual needs of rights-holders and users of materials in digital libraries (LC, 1999).

The challenge here is, in part, to address legal issues of Intellectual Property associated with access, copying, and dissemination of physical and digital materials. Information professional should develop mechanisms for acceptable use policies, codes of practice, and standard contracts that begin to establish norms of behavior by people creating and using digital library resources. After a long time, the Bangladesh Copyright Act, 1974 has been amended on July 9, 2010 called “Copyright Law 2000” (IPFrontline.com: 2010). It is expected that the law will help writers, artists, filmmakers, musicians, producers, publishers and computer software companies to protect their copyrights. The law provides for maximum punishment of four years' imprisonment and fine of TK 200,000 (approx. USD \$3,933.14) in cash for violation of the copyright rules. Another challenge is the successful implementation of the act; and ethics of the information professionals.

\section{Challenge Six: Integrate access to both digital and physical materials.}

A user looking for an item in a library catalog should be able to identify it without regard to whether it is available in its original physical form or as a digital or microfilm reproduction. Intellectual descriptions of originals and reproductions should be presented in a fully integrated way without which the digitization efforts may be disconnected from traditional library services. The lack of such synchronization exists in the library systems in Bangladesh. In most cases, records of paper based and digital content (metadata and text) are maintained separately which results in coordination in record management and query processing.

\section{Challenge Seven: Develop approaches that can present heterogeneous resources in a} coherent way.

A digital library provides a wide variety of contents that are heterogeneous in terms of original format, digital format and resolution, level of descriptive information and access support. Accumulation and repackaging of these diversified formats in digital library system is really a challenging job due to the emerging technologies. The current scenario of digitization program in Bangladesh prevail that institutions basically include in-house publications, research reports, old publications and in most cases excludes articles, pamphlets, personal papers, legislative documents, prints, architectural drawings, photographs, maps, sheet music, sound recordings, and movies etc. Thus the challenges will occur with the policy decisions to include diversified content and evolution of diverse technologies of digitization. 
Challenge Eight: Make the Digital Library useful to different communities of users and for different purposes.

Digital library should be open for authorized users but must be user friendly and respond to multi-faceted query. It indicates the design challenges that encompass user customization of interface, strong vocabulary with efferent mapping etc. Most of the digital preservation initiatives in the country are based on package programs and allow a little for customization.

Challenge Nine: Provide more efficient and more flexible tools for transforming digital content to suit the needs of end-users.

Today many digital objects are hard to transform system to system and fly over the network and Internet. That is why digital libraries is represented in multiple forms or versions. The multiple forms exist to serve varieties of users, function as archival masters, and reduce download time and transmission loads on networks. This plural production and maintenance may be burden to the authority having less financial capability in the developing countries like Bangladesh.

\section{Challenge Ten: Develop economic models to support sustainable digital preservation programs.}

The creation and maintenance of digital libraries is very expensive. Costs are incurred for production, for ongoing provision of access, and for preservation of the digital information. The cost to develop and operate a distributed architecture for long-term archiving, migration, and backup of digital materials will be high. Thus the greatest challenge toward digitization programs in Bangladesh is the continuing cost of assembling content and providing access to the inhabitant of the country. Considering the socio-economic condition of Bangladesh, it is virtually impossible to develop digital libraries over night in the country. They should precede foreword with a long-range planning.

\section{Challenge Eleven: Building Digital Collection through coordinated scheme}

One of the biggest issues in creating digital libraries will be the building of digital collections. There are essentially three methods of building digital collections (Cleveland G: 1998, p.5):

i. Digitization: converting paper and other media in existing collections to digital form.

ii. Acquisition of original digital works: created by publishers and scholars. Example items would be electronic books, journals, and datasets.

iii. Access to external materials: not held in-house by providing pointers to Web sites, other library collections, or publishers' servers.

The first two methods, doing in-house digitization and acquiring digital works, are expensive particularly to undertake alone. By working together, institutions with common goals can gain greater efficiencies and reduce the overall costs. It also reduces the redundancy and waste of acquiring or converting materials more than once. Unfortunately we find no initiative for digital collection building in a coordinated scheme among the similar type of libraries. 


\section{Bangladesh Journal of Library and Information Science}

\section{Challenge Twelve: Penetration rate of computer and internet users}

According to International Telecommunication Union (ITU) statistics, up to September, 2009 there were 556000 Internet users in Bangladesh which is only $0.4 \%$ of its total population. The statistics has also reported that there were 995,560 Internet users as of Aug/2010, 0.6\% penetration, per FB (ITU: 2009). Only 1.5\% population has access to computer. Here it is to be mentioned that most of computer and Internet user are the inhabitant of urban areas. So it is very difficult for libraries to replace the traditional library materials with digital contents unless the major portion of the population has accessibility to computer and internet. Low economic condition, poor ICT infrastructure, socio-political instability etc. are the major forces to this vulnerable situation.

\section{Challenge thirteen: Weak ICT Infrastructure}

ICT infrastructure of a country is directly related to the communication systems. One of the foremost challenges to materialize the Digital Bangladesh Vision 2021 would be to ensure overall connectivity at affordable cost. With the intent to enhance connectivity emphasis should be given on the establishment of infrastructures to "connect the unconnected" More importance may be given on laying more optical fiber to reach the marginal people of the country particularly the rural areas. According to the world fact book of the Central Intelligence Agency (CIA): during the period of 2003 to 2009 land phone users of Bangladesh has been raised from .50 to 1.522 million while revolutionary changes have been occurred in the cell phone subscribers (2.83 million to 50.4 million). In the world comparison index the position of Bangladesh relating to cell and land phone usage is 22 and 62 respectively (CIA: 2010) . Wireless broadband Internet services remain virtually non-existence in the country. However, after granting a number of WiMAX licenses in 2008, a considerable optimism noticed in the WiMAX networking particularly in Dhaka and some other divisional and district head quarters (BuddeComm: 2010). According to BTRC authority $1800 \mathrm{KM}$ fiber optic cable under Bangladesh Railway is being utilized by the private mobile telephone operatorGrameen Phone. Recently the govt. has also decided to give license for long distance telecom services Voice of Internet Protocol (VOIP) Licenses. There are 6 satellite earth stations and about 468,000 KM of sub-marine cable has been linked to the landing station at Cox's Bazar under SEA-ME-WE4 with 64 STM-1 (10 gbps) capacity (Rahman, H. 2006. 2). The overall development of telecommunication systems in the country is progressing. However, the internet bandwidth and subscription rate is still beyond the capacity of general people. Though private mobile phone operators offers country wide (at the village level also) internet services, the higher price hinder its popularity among the general people. However, It is hopeful that the government has already initiated a National Infra-Network Project for Bangladesh Government (BanglaGovNet) to connect the ministries/divisions, departments, districts and Upazilas to establish the public network for the effective implementation of e-Governance in the country (Planning Commission, 2010, p.117). Another aspiration is that the government recently has undertaken some initiatives having a long range goal vision 2021. In the ICT sector the plan includes establishment of computer lab at primary and secondary school by 2014; increase tele-density to 70\% in 2015 and $90 \%$ in 2021; expansion of broadband to 30\% in 2015 and 40\% in 2021; introduce Wireless Broad Band (Wi Max) across the country by 2015 (Planning Commission, 2010, p.119) 


\section{Challenge fourteen: Electricity failure}

Electricity or power failure is directly related to the ICT infrastructure. We dare to discuss the issue as separate heading because overcoming the electricity crisis is one of the most challenging jobs of the government in the recent times. Bangladesh is facing huge load shedding of electricity. Bangladesh's installed electric generation capacity was 4.7 GW in 2009; only three-fourth of which is considered to be 'available'. The government has failed to add new power plants over the last decade against the increasing demand of electricity. Now almost all parts of Dhaka have at least four to five hours load shedding of electricity everyday let alone the other parts of the country. It is seriously affecting all the electricity dependent sectors as well as hampers technology based information systems and ultimately impede the progress toward "Digital Bangladesh".

\section{Challenge fifteen: Skilled Manpower}

Skilled manpower is one of the prerequisite of the successful implementation of digitization and digital information system. Besides traditional librarianship, digital preservation systems and services requires some basic working knowledge from the professionals such a scanning, OCR (Optical Character Recognition), Online procurement and use of e-books and e-journals, maintaining bibliographical and full text databases, searching and retrieval, web design and hosting, etc. Unfortunately working knowledge regarding ICT based library systems among the practicing librarians and supporting staff is still below the expected level. The major part of the information workers in the country seldom has practical ideas on digitations and digital librarianship. So, switching the traditional librarians to digital librarians is one of the key challenges toward digitization in our country. The information professionals and their higher authority should recognize this need and take necessary action for refresher training. In this case they can consult with persons or institutions that have the dual expertise (Librarianship and ICT).

\section{Conclusion}

Comparing to other sectors, Bangladesh is lagging behind in digitization and establishment of digital information systems. Technology-based library and information systems are still in its infancy in the country. The Establishment of such systems is of difficult, expensive and longterm process. Due to resource constraints, it becomes difficult for many organizations to provide necessary financial support for initial setup. Lack of standard and efficient manpower, in most of the cases, organization has to depend on third party for digitization and hosting them over web. It also sometimes creates misconception among the professionals in digital librarianship, library automation and even technology based information systems. Extreme shortage of electricity, limited network coverage, higher price of internet connectivity, bandwidth, and ICT components are the major infrastructural challenges toward digital information systems. As digitization is a long-term process, socio-political stability is badly required for the success story of digitization programs and to make vision 2021 into reality as a whole. To reach the destination all parties- library authority, library educator, political parties and end users- are to realize its importance, eliminate techno phobia, superstition and work together with care. 


\section{Bangladesh Journal of Library and Information Science}

\section{References}

Cleveland G. (1998). Gary Cleveland. Digital Libraries: Definitions, issues, and Challenges. - Ottawa, CA - IFLA, 1998.

LC (1999). The Library of Congress. Challenges to Building an Effective Digital Library. Accessed online on 25/01/2011 at URL: http://memory.loc.gov/ammem/dli2/html/lcndlp.html

IPFrontline.com: (2010). IPFrontline : IP and Technology Magazine. issue: Fri, Jul 14, 2010 accessed online on the 25/01/2011 at URL: http://www.ipfrontline.com/depts/article.aspx?id=1235\&deptid=6\#

Planning Commission (2010). Government of The Peoples Republic Of Bangladesh. Outline Perspective Plan of Bangladesh 2010-2021: Making Vision 2021 a Reality - Dhaka - General Economic Division, 2010

ITU ( 2010). International Telecommunication Union (ITU). Intranet World Stats: usage and population statistics. URL: http://www.internetworldstats.com/asia/bd.htm/ (Aaccessed online on 25 August, 2010

Rahman (2006). Rahman, H. 2006. Access and infrastructure issues: context Bangladesh in ICT4D Status Report 1.0. Dhaka: SDNP Bangladesh, 2006. URL- http://www.sdnbd.org [Accessed on 03/08/2007

CIA (2010) .The Central Intelligence Agency (CIA). The world factbook. url: https://www.cia.gov/library/publications/the-world-factbook/geos/bg.html [accessed on 15, September, 2010]

BuddeComm (2010). BuddeComm. Bangladesh - Telecoms, Mobile, Broadband and Forecasts. url: http://www.budde.com.au/Research/Bangladesh-Telecoms-Mobile-Broadband-and-Forecasts.html accessed on 15 September, 2010.

Ministry of Education (2010). Government of the People's Republic of Bangladesh. National Education Policy - 2010. Dhaka, Ministry of Education.

MoSICT (2008). Ministry of Sciences, Information and Communication Technologies. National ICT Policy 2008 (Final Draft). Dhaka : MoSICT, 2008. 